\title{
Urgences
}

\section{Un certain retour}

\section{James Paulin}

Numéro 3, 4e trimestre 1981

URI : https://id.erudit.org/iderudit/025045ar

DOI : https://doi.org/10.7202/025045ar

Aller au sommaire du numéro

Éditeur(s)

Urgences

ISSN

0226-9554 (imprimé)

1927-3924 (numérique)

Découvrir la revue

Citer ce document

Paulin, J. (1981). Un certain retour. Urgences, (3), 55-58.

https://doi.org/10.7202/025045ar

Ce document est protégé par la loi sur le droit d'auteur. L'utilisation des services d'Érudit (y compris la reproduction) est assujettie à sa politique d'utilisation que vous pouvez consulter en ligne.

https://apropos.erudit.org/fr/usagers/politique-dutilisation/
Cet article est diffusé et préservé par Érudit.

Érudit est un consortium interuniversitaire sans but lucratif composé de l'Université de Montréal, l'Université Laval et l'Université du Québec à Montréal. Il a pour mission la promotion et la valorisation de la recherche. https://www.erudit.org/fr/ 
JAMES PAULIN 


\section{UN CERTAIN RETOUR}

Un retour tout-à-fait incertain en ce vieil antre farci de mythes et sous les lumières $y$ ayant trouvé refuge qu'un seul et tendre amour

On y flaire très fort encore la trace l'empreinte de ce qu'il faut brûler la mémoire des cauchemars tenaces vestige du musée des frasques

La mer a conquis ses montagnes le pêcheur tendu ses filets le lointain secret des années tristes s'accole tendrement au geste des yeux

Si la voie est à jamais aveuglée dans la fuyance des espaces ne faut-il devant l'évidence qu'être seul à ravaler les sanglots à poser un pas tremblant songeur sur le chemin des enfants 


\section{JE VOUS AI VUE}

Je vous ai vue belle étrangère un soir au bar du Transit je volais sans connaître de pied-à-terre et dans mes yeux un rideau de buée gardait un silence grandiose

Vos bras comme des boas psychédéliques s'entrelaçaient sur la chaleur de votre sein et qu'hypnotisait un poisson d'or pendant superflu de votre cou

Vous aviez je ne sais pourquoi sur la tête un chapeau à larges bords d'où s'échappaient de rebelles boucles rousses à la façon d'ophidiens chimériques

La poussière du chemin baignait tout entière dans le vert de vos regards et c'est conquis que je refis ma route avec en tête la bouche du désir

$\mathrm{J}$ 'avais depuis longtemps perdu la clef de fer de ma maison et comme par la grâce d'un Sésame avez omis fidèle d'y mettre la forme (et) c'est sauvages que nos ombres se suivent depuis la sortie du bar 


\section{FINALE}

La fin d'une lignée trop longue le bout d'un étroit chemin I'hiver mangera toujours à ma table comme l'invité imperturbable de ce qui s'échappe

La chaleur passagère a quitté mon logis victime d'orages imprévus elle portait le germe du malaise une source de bien-être louvoyant

Une solitude dans cette épaisse nuit où les cafards tapissent les murs les enfants s'emmurent au soleil comme des taupes crevassant la sphère

Que serait-ce encore que d'être l'épaule appuyée tout contre le néant des attentes le crâne vide de toute substance et farci de silences minéraux les yeux révulsés vers des cieux hermétiques

L'on se doit pourtant le mot d'amour sinon pour garder vive la plaie des mythologies au moins pour tromper l'attente l'espoir des perce-neige en janvier 